The Geneva Papers on Risk and Insurance, 22 (No. 83, April 1997) $177-186$

\title{
About the Insurability of Catastrophic Risks*
}

\author{
by Christian Gollier**
}

\section{Introduction}

For several years now, The Geneva Association has supported research dealing with the problem of the insurability of catastrophic risks. Insurers have great concern about how their activities, dealing with covering potentially catastrophic losses, may affect their survival in the medium and long run. Some (re)insurers stopped insuring that kind of risk, thereby prompting a wave of insurability crises, as the liability crisis in the US. Others did not stop business in these sectors. Some of them went into financial trouble, as the Lloyd's of London. Most States were forced to intervene to organize coverage, sometimes through a very inefficient system with only a tiny dose of (ex ante or ex post) risk prevention.

Howard Kunreuther (1986) has provided us with an interesting analysis of the origin of the insurability crisis for catastrophic risks. He also offers a stimulating proposal to manage these risks with the help of insurers. In this comment to Kunreuther's paper, I want to reassess the characteristics of catastrophic risk that make them difficult to insure. Gollier (1996) examines the several reasons that may generate a problem of insurability, as the risk of fraud (observability), moral hazard and adverse selection. Whereas catastrophic risks may be affected by these problems, I prefer here to focus on what is specific to most of the catastrophic risks, that is, large losses, low probabilities, limited liability and ambiguity.

We define a risk as being uninsurable if, given the economic environment, no mutually advantageous risk transfer can be exploited by the consumer and the suppliers of insurance. Partial uninsurability occurs when the parties can exploit only part of the mutually advantageous transfer of risk. We start the analysis with a quick review of the classical theory of risk sharing which provides a general, well-established framework to examine the insurability problem.

\footnotetext{
${ }^{*}$ I thank Howard Kunreuther for helpful comments. Financial Support from the Chair of Insurance of the FFSA at IDEI is acknowledged.

** Professor at GREMAQ and IDEI, Université de Toulouse, France.
} 


\section{The classical model of efficient risk sharing}

Economists ${ }^{1}$ have developed during the last thirty years a canonical model to deal with optimal insurance/risk-sharing and risk prevention. Our aim in this section is to review the assumptions and basic results of this simple model.

In the classical risk-sharing model, there is a large number of agents in the economy. Each agent has a risky endowment. Correlation among these risks is allowed. Agents are expected-utility maximizers, with an increasing and coverage utility function. The following assumptions are made:

- There is no transaction cost.

- The distribution function of risks is common knowledge.

- The distribution function can depend upon prevention efforts by the agents. Efforts are observable at no cost.

- The model is static, or there exists a complete set of insurance markets for future risks.

Under these conditions, we obtain the following wellknown results:

- Every agent is able to find the level of coverage that he/she wants at the equilibrium price of insurance. The level of coverage is socially efficient. In particular, if there is no systematic risk in the economy, the aggregate wealth is certain, and by the mutuality principle, so will be the individual wealth levels: there is full insurance for everyone at equilibrium. If a systematic risk exists, its sharing in the population satisfies a simple risk-sharing rule: the sensitivity of an individual's final wealth to the aggregate wealth in the economy is inversely proportional to its Arrow-Pratt degree of absolute risk aversion. In particular, if there is a risk-neutral agent in the economy, he/she will bear $100 \%$ of the systematic risk, thereby fully insuring the population. ${ }^{2}$

- Despite risks depending upon efforts to prevent them, there is no moral hazard problem. Indeed, since efforts are observable, each party will condition the acceptance of the contract to strict requirement on risk prevention by the other party. Contractors will privately trade-off their cost of effort to the benefits of risk-sharing generated by the contract.

We conclude that in the classical problem of insurance and risk prevention, there is no need for public intervention. Risks are efficiently spread throughout the economy. This means, in particular, that agents are fully insured if risks are diversifiable, or if there exists a risk-neutral agent in the economy. Also, agents get the good incentives to invest in a socially efficient level of risk prevention. These results do not fit with the real world. In the next sections, we review the reasons why the classical model fails to explain why some catastrophic risks are not insurable.

\section{Transaction costs and undiversifiable risks}

The prevalence of transaction costs in the insurance industry is a well-established fact. For many insurance lines like automobile insurance, transaction costs amount up to $30 \%$ of the premium. They correspond to general administrative costs, the cost of capital, the cost

\footnotetext{
${ }^{1}$ See Borch (1962), Arrow (1953), Mossin (1968), Raviv (1978) and Gollier (1993).

${ }^{2}$ See Eeckhoudt and Gollier (1995) for a synthesis on Pareto-efficient and competitive risk-sharings.
} 
of marketing, the cost of claim-adjustment and court costs. Taxes are also an important source of transaction costs. These costs are eventually passed on to the policyholder through a loading on the premium.

How do transaction costs affect the insurability of risks? There is no doubt that some individuals with a low degree of risk aversion will find these costs too expensive with respect to the benefit of the coverage. In fact, Mossin (1968) proved that it is never optimal to purchase full insurance when the premium contains a loading. Thus transaction costs are a source of partial uninsurability.

More interestingly, Arrow (1965) showed that the optimal form of insurance contract is a contract with full insurance above a straight deductible if the loading only depends upon the actuarial value of the contract, i.e. the expected indemnity. Deductible insurance is a best compromise between the willingness to cover larger risk and the objective to limit transaction costs. The intuition is that the willingness to pay for coverage depends upon the variance of losses. When one reduces the size $t$ of the risk, the willingness to pay for insurance decreases as $t^{2},{ }^{3}$ whereas deadweight transaction costs decrease as $t$. It implies that only large risks are insured. This is in contradiction with the observation that one has no problem finding insurance against cracks in one's windshield, but one cannot find insurance against much larger risks such as long-term unemployment. We conclude that the existence of transaction costs is not a convincing explanation for insurance market failures for large risks.

One can link the argument of transaction costs to the one on undiversifiable risks. Obviously, many natural, environmental or technological risks are in the class of large risks that are difficult to eliminate by using the mutuality principle. Moreover, insurance companies will not provide fair insurance premiums for these risks. Indeed, shareholders will not be able to diversify the risk associated with dividends paid by insurance companies that cover these large risks. They will ask for a risk premium, which will increase the cost of capital of these companies. This cost will be passed on to policyholders through a larger premium rate for the component of individual risks that is systematic. It will induce them to retain part of their individual risk. In short, the fact that the risk is systematic induces insurance premiums to contain a positive loading that has an effect equivalent to a transaction cost. This is the logic behind larger deductibles for systematic risks.

Still, the fact that many environmental and technological risks have a systematic component does not explain the observation that they are often entirely retained by the initial riskbearer. This is not compatible with the mutuality principle. It is said that insurers are reluctant to enter into insurance lines with potentially catastrophic losses because of their limited reserves to face these risks. This argument does not take into account reinsurance chains that would spread risks worldwide. After all, even the worst scenario of a "Big One" earthquake in downtown San Francisco would cost 100 billion dollars, which means a $\$ 400$ loss per US citizen if the risk is perfectly diversified in the country, not mentioning international diversification. A more convincing argument would be that the reinsurance industry faces transaction costs at any element of the chain. This would strongly limit the efficiency of reinsurance and the possibility to spread risk on insurance markets. The question is then why insurance companies with a well-diversified ownership structure are unable to raise enough reserves on financial markets to underwrite such risks? This question is left for future research.

${ }^{3}$ This is specific to the Expected Utility model and to other models that satisfy second-degree risk aversion, a concept defined by Segal and Spivak (1990). 


\section{The insurance of low probability events}

Low-probability events may be difficult to insure. Kunreuther (1996) suggests that there is a threshold probability below which a person will not care about the corresponding risk. We show in the Appendix that the standard insurance problem with a risk-neutral insurer and with transaction costs does not yield this property. Rather, we show that the optimal level of insurance is a decreasing function of the probability of an accident, at least for low probability events. This is consistent with the findings of Eeckhoudt and Gollier (1996) that when an agent faces several independent sources of risks, he will select a smaller deductible for risks that have a smaller probability of occurrence. This means that risk-averse agents are more willing to insure against infrequent events. The reason is that the insurance premium by a risk-neutral insurance industry will be proportional to the probability of loss. This makes it relatively cheap to insure against low-probability events.

We conclude that the fact that the event has a low probability of occurrence may not explain why it is difficult to insure.

\section{Limited liability}

An individual can cause damage to others, either in the course of his/her profession (medicine, surgery, house-building,...) or because of other activities (e.g. driving a car). The same kind of external random effect occurs for firms. In most countries, the agent found liable for damage to others must indemnify them accordingly. This is done to force decision makers to internalize all costs generated by their choice. But indemnification is possible only up to the decision maker's financial capacity. Limited liability is a way to protect risk-takers against an excessive financial distress. But it has long been recognized that limited liability distorts the decision of the risk-taker in a way that is socially inefficient. The US Savings and Loans crisis is often explained by the fact that "zombie" S. and Ls adopted in the early eighties a very risky attitude in an attempt to "bet for resurrection" after some blows to their portfolio of (real estate) assets. This is because limited liability gives the agent the equivalent of a free put option. Put it in simpler terms, under limited liability, an insolvent agent can only benefit from taking more risk, because he does not bear the burden of losses. Therefore, if he is risk-neutral, he will seek to maximize the expectation of a convex function of his wealth. As a result, he will systematically exhibit a risk-loving behavior, and adopt a very risky attitude. This is a kind of moral hazard problem. Risk aversion mitigates this result, but only for agents who are well capitalized, as shown by Koehl, Gollier and Rochet (1997).

The effect of limited liability of the policyholder on his demand for insurance is thus unambiguous: if he is risk-neutral, it is never optimal to cover a risk of loss, even in the most favorable case where the premium rate is fair. Insuring the risk would yield a sure reduction in wealth equaling the expected loss. Not insuring the risk would yield an expected reduction of wealth that is less than it, since the agent bears only part of the risk of loss. Another way of looking at this problem is that the insurance contract creates a "deep pocket" where victims can find compensation for their losses. This kind of problem is particularly crucial when examining the demand of insurance by firms for catastrophic environmental risks. limited liability on the part of the insurance also reduces the demand for insurance, since it makes the indemnity dependent on its solvency. 
Limited liability thus raises several important questions. How to organize compensation for those who bear the negative externalities? How to build an incentive-compatible mechanism that increases loss prevention by decision makers with limited liability? How to solve the market failure of liability insurance markets? How to force firms not to under-capitalize their subsidiaries which are in charge of managing the riskiest part of the business? Two routes have been used. The first one is compulsory insurance. This solves the misallocation of risk in the economy and the organization of a system to compensate the victims. But, most of the time, compulsory insurance has been funded by a flat, non-discriminatory, nonincentive-compatible insurance tariff. The policyholder's investment in loss prevention is not observed by the fund, either because it is difficult to get information on it, or because the fund did not get the good incentive to organize an incentive-compatible system.

The second route has been to organize a "deep pocket" for decision makers. This means, for example, that the hospital who employs an uninsured physician will be made liable in case of the physician's insolvency. Under the US CERCLA, when a bank has been relatively closely involved in the monitoring of a firm's activities, it may be considered by the courts as liable for cleaning up the environmental damages generated by the insolvent firm. The objective of this strategy is to force risk-takers to internalize the full cost of potential losses: the hospital will reduce the income of the careless physician, and banks will increase the loan rate of riskier firms. If there is no asymmetric information between the principal (the hospital, the bank) and the agent (the physician, the firm), the agent will select the socially efficient level of care and insurance. There would be no more insurability problem. But, as observed by Boyer and Laffont (1995), there is no reason to believe that the principal can monitor the agent at no cost. The CERCLA legislation, for example, introduces more asymmetric information on credit markets. Consequently, there will be more credit rationing, the cost of capital will be larger, and the structure of banking contracts for firms will be affected. Is insurability worth this cost?

\section{Ambiguity}

There are many instances in which the random variable describing the risk has no objective probability distribution. This can be due to the absence of historical data. Or because of our imperfect scientific knowledge, for those who believe in a deterministic world. To illustrate, who knows the actual probability distribution of a major leak in some specific type of nuclear plan, the probability of transmission to the human being of the so-called "mad cow" disease, the probability of failure of the new European satellite launcher Ariane $\mathrm{V}$, or the probability of accident of a new inexperienced driver? This can also be due to a volatile environment, as is the case for future liability rules of the environmental policy. The ambiguity about the probability distribution raises several questions. How to calculate a fair insurance premium? How to evaluate the benefits of an insurance contract for the insuree? What would be an efficient allocation of risks in the economy?

The defenders of the orthodox theory claim that ambiguity is no problem. Namely, the Subjective Expected Utility model states that, under some simple axioms on the behavior of the agent under uncertainty, he will use some subjective probability distribution to evaluate his welfare. For example, the inexperienced driver will use some subjective probability of accident, say $15 \%$, to determine his optimal deductible and his optimal investment in prevention. The potential problem, however, comes from the fact that the insurer may have different prior beliefs, say $20 \%$, about the probability of accident of this specific type of 
inexperienced driver. If the two parties "agree to disagree" on their respective prior beliefs, the model simplifies to the analysis of the effect of the insuree's optimism on his insurance demand. In this particular example, the policyholder will observe the excessive probability of an accident used by the insurer as an additional loading factor to the premium calculation. Consequently, the agent's demand for insurance will be smaller than if the beliefs were the same. At the limit, the agent may prefer not to insure the risk. Ambiguity would be a source of uninsurability. On the contrary, if the a priori probability of an accident is larger when estimated by the policyholder than by the insurance company, the demand for insurance will be increased. Since there is no specific reason why to believe that consumers are intrinsically more optimistic than insurance companies, the argument still has to be refined to provide a credible explanation for uninsurability.

Notice that supply and demand can convey information about the size of the risk when the two parties have some private information on it. For example, a large premium rate can provide information to the consumer that his risk is, in fact, larger than he believes. However, this can be a strategical behavior by the insurer to influence the beliefs of its policyholders. This could provide an explanation to why insurers seem more pessimistic than their policyholders, yielding uninsurability as a temporary equilibrium.

There is another explanation to why ambiguity may lead to an insurability problem. Ellsberg (1961) noticed that a large population of agents violates the prediction of the Subjective Expected Utility Theory. Namely, they seem to have a bias in favor of decisions that eliminate the possibility of facing ambiguous distributions. For example, the inexperienced driver can eliminate using subjective probabilities to compute welfare by purchasing full insurance. This concept is called "ambiguity aversion". It drastically differs from the concept of risk aversion which is related to a preference for sure wealth. If only the policyholder is ambiguity-averse, this is a factor for an increase in the equilibrium coverage of insurance. If, on the contrary, only the insurer is ambiguity-averse, this is a factor of uninsurability. The concept of ambiguity aversion has received a precise theoretical content by the works of Gilboa and Schmeidler (1989).

\section{Dynamic aspects of insurability}

\subsection{Realized risk}

In many circumstances, risks borne by agents are not independent through time. For example, my health status tomorrow is affected by my health status today. Thus, health insurance will be more expensive for people with a poor current health. The extreme form of this is a "realized risk" in which the evolution of the random variable in the future becomes deterministic, given the current situation. Obviously, there exists no mutually advantageous risk transfer in this case. In short, one cannot insure a risk ex-post.

External information on the scale of a risk can yield the same effect. Genetic testing will soon inform us about the evolution of our health. If this information is made available to the market, the scope of insurance will be much reduced. Hirshleifer (1971) already noticed that more information can have a negative value for society. Early information on risks will make these risks uninsurable. This so-called "Hirshleifer effect" may be escaped if insurance could be organized prior to the revelation of the information. Whether the outcome of genetic tests will be insurable in the future is central for the future of life and health insurance systems. In France, the prohibition of genetic information revelation to insurers is 
considered by the legislator. This would, for sure, have a dramatic consequence for insurance markets because it would introduce an incredible amount of adverse selection. Only those with a bad genetic profile will be willing to purchase insurance, raising the break-even premium rate, thereby excluding good risks from the market. The same kind of problem will occur if one improves the ability to forecast future earthquakes, or other natural disasters.

This phenomenon indicates the importance for insurance markets to establish longterm relationships between the buyer and the seller of a risk. Health insurance would have a much smaller value if, at any time, one party could renege the contract. This links this discussion to the assumption made in the classical model that future risks exist in insurance markets. The problem here is our inability to insure future generations against future. They are simply not present in markets to purchase insurance contracts. This is a particularly important problem for environmental and technological risks.

\subsection{Precautionary reserves and time diversification}

Risks can be transferred between individuals, but they can also be transferred through time via the credit markets. Individuals can forearm themselves in the face of uncertainty by saving. Under some technical conditions developed in Gollier and Kimball (1996), precautionary saving and insurance are substitutes, i.e. the insurability of the future risk reduces the willingness to save. As shown by Yaari (1976), an agent with an infinite time horizon and with risks that are independent through time would "time-diversify" his risks by an efficient borrowing-lending strategy that perfectly smooths his consumption through time. No insurance would be necessary in this case. Risks would be uninsurable by lack of insurance demand. But households have finite time-horizon. They face risks that are dependent from one period to another. These two effects limit the efficiency of time-diversification, which provides room for insurance.

The "time-diversification" strategy is also difficult to implement because credit markets are not perfect. In particular, agents face a liquidity constraint, i.e. they cannot borrow a large amount of money in case of an "early hit" of damages. Deaton (1991) shows that the existence of a liquidity constraint may have a very large effect on the variability of the optimal consumption plan when there is no insurance available. The liquidity constraint that consumers face on credit markets is thus an important determinant of the demand for insurance.

Gollier (1994) examines the optimal dynamic strategy of a risk-averse agent bearing an insurable risk to determine whether precautionary saving is superior to insurance in the long run. In his model, the risk of loss follows a Poisson process. In the short run, the optimal strategy is to transfer most of the risk to the insurer, because the agent does has not have enough financial reserve to be used in case of an "early hit" of damages. If he is sufficiently lucky, and if his consumption rate is low enough, he will be able to accumulate more reserves that will allow him to retain a larger proportion of the risk in the future. This is desirable, because reserves generate a positive expected return, and because insurance is costly. Gollier (1994) characterizes the best compromise between two conflicting objectives in the short run: protecting the agent against large losses and raising reserves to reduce the cost of the risk in the future by reducing insurance coverage. These objectives conflict because the first is attained through spending enough money for insurance and the second saves on insurance costs today. Gollier shows that the demand for insurance vanishes in the long run if transaction costs on insurance markets exceed a critical positive value. 
This model can be reinterpreted for large firms funding an insurance captive to organize risk retention, together as for insurance companies determining their strategies of capital accumulation and reinsurance. A starting insurance company has a low capacity to retain risks. It is thus forced to reinsure a large part of its business. If it is not caught by an "early hit" of catastrophic indemnities, its capacity to retain risk will grow. This will increase the capacity of the market.

The ability of insurance companies to transfer wealth through time is thus central for organizing time diversification of catastrophic risks. But the modern theory of corporate finance indicates that managers in firms with a large financial reserve will be less efficient than managers in less capitalized firms where their job is at stake. Managerial inefficiencies open the door to raiders who could use the cash reserve of the insurance company for their own purpose. The bottom line is that it can be hard for insurance companies to accumulate financial reserves. This has an adverse effect on the capacity of the insurance market.

\section{Conclusion}

Insurance plays a key role in the functioning of our modern economies. Insurance contracts transfer individual risks to financial markets through shareholders of insurance companies. It allows for a reduction of risks borne by society through diversification. It also allows for transfering risks to agents who have a comparative advantage to bear risks, i.e. more risk-tolerant agents. The added value for the economy is considerable: it directly increases the welfare of the risk-averse policyholders, but it also induces risk-averse entrepreneurs to invest more in risky activities, thereby increasing growth and employment.

This view on the functioning of our economies is idealistic. There are several reasons why a large proportion of uncertain events cannot be insured efficiently by competitive insurance markets. Transaction costs are an obvious reason for this. The fact that losses can be very large is not, in itself, a convincing argument explaining the limits of insurability. Indeed, the larger are potential losses, the larger is the risk premium that the consumer is ready to pay to get rid of the risk. Similarly, the expected utility theory cannot explain why it seems to be relatively more difficult to insure low probability events.

Limited liability for the risk-taker is a potential explanation for why some risks are not covered by an insurance contract. The consequences of limited liability on risk prevention and insurance demand can be controlled by imposing a "deep pocket" rule for decision makers, but this policy can have some adverse effects.

The fact that insurers and consumers may perceive risks differently is another source of uninsurability if insurers are more pessimistic than consumers, or if insurers are more ambiguity-averse than consumers. The fact that many have a dynamic nature can explain uninsurability. One should help markets offer opportunities to build long-term relationships between policyholders and insurers. This is how consumers will be able to cover risks that may have a long-term effect on their welfare. 


\begin{abstract}
APPENDIX
We show here that the demand for insurance is decreasing with the probability of loss, at least in the case of low probability events and with increasing absolute risk aversion (IARA). More precisely, we show that, under IARA, the optimal deductible is an increasing function of $p$, the probability of accident, in the neighborhood of $p=0$. We use three assumptions: first, the policyholder is an expected-utility maximizer with an increasing and concave utility function $u$. Second, contrary to the model by Kunreuther (1996), both the insurer and the policyholder know the true value of $p$. Third, the premium contains a loading that is proportional to the actuarial value of the policy.

The agent has an initial wealth $w_{0}$. He/she faces a risk loss $L$ with probability $p$. He/she is offered a continuum of insurance contracts. Each contract is characterized by a deductible $d \in[0, L]$ and a premium $P=\lambda p(L-d)$, where $\lambda>1$ is the loading factor. The agent maximizes his/her expected utility, i.e.
\end{abstract}

$$
\max _{d} H(d, p)=p u(A(d, p))+(1-p) u(B(d, p)),
$$

with $A(d, p)=w_{0}-d-\lambda p(L-d)$ is wealth in case of an accident, and $B(d, p)=w_{0}-\lambda p$ $(L-d)$ is wealth without an accident. The first-order condition for this problem is written as

$$
\frac{1}{p} \frac{\partial H}{\partial d}=-u^{\prime}(A)+\lambda E u^{\prime}(\tilde{w})=0
$$

where $\bar{w}$ takes value $A$ or $B$ with probability $p$ and $1-p$ respectively. This equation gives the optimal deductible $d(p)$ as a function of the probability of loss. When $p$ tends to zero, condition (2) yields.

$$
u^{\prime}\left(A_{0}\right)=\lambda u^{\prime}\left(B_{0}\right),
$$

with $A_{0}=A(d(0), 0)$ and $B_{0}=B(d(0), 0)$. It implies that $A_{0}$ is smaller than $B_{0}$, i.e. $d(0)$ is positive.

Because $H$ is concave in $d, d^{\prime}(p)$ has the same sign as $\frac{\partial^{2} H}{\partial d \partial p}$. This cross-derivative of $H$ has the same sign as

$$
\lambda(L-d) u^{\prime \prime}(A)(1-\lambda p)-\lambda^{2}(L-d)(1-p) u^{\prime \prime}(B)+\lambda\left(u^{\prime}(A)-u^{\prime}(B)\right) .
$$

When $p$ tends to zero, this is rewritten as

$\lambda(L-d)\left(u^{\prime \prime}\left(A_{0}\right)-\lambda u^{\prime \prime}\left(B_{0}\right)\right)+\lambda\left(u^{\prime}\left(A_{0}\right)-u^{\prime}\left(B_{0}\right)\right)$.

Using condition (3), this is equivalent to

$$
\left.\lambda(L-d) u^{\prime}\left(A_{0}\right) 6 R\left(B_{0}\right)-R\left(A_{0}\right)\right)+\lambda u^{\prime}\left(B_{0}\right)(\lambda-1),
$$

where $R(w)=-u^{\prime \prime}(w) / u^{\prime}(w)$ denotes absolute risk aversion. The second term is always positive. Because $B_{0}>A_{0}$, the first term is positive under increasing absolute risk aversion. Thus, under IARA, an increase in the probability of a low probability event induces the policyholder to increase his choice of deductible. 


\section{REFERENCES}

AASE, K. K., (1993), "Equilibrium in a Reinsurance Syndicate: Existence, Uniqueness and Characterization", Astin Bulletin, 23, pp. 185-211.

ARROW, K. J., (1953), "Le rôle des Valeurs Boursières pour la Répartition la Meilleure des Risques", Edition du CNRS, Paris.

ARROW, K. J., (1965), Aspects of the Theory of Risk Bearing, Yrjo Jahnsson Lectures, Helsinki. Reprinted in Essays in the Theory of Risk Bearing (1971), Chicago: Markham Publishing Co.

BORCH, K., (1962), "Equilibrium in a Reinsurance Market, Econometrica, 30, pp. 424-444.

BOYER, M. and LAFFONT, J.-J., (1995), "Environmental Risks and Bank Liability", mimeo, University of Montréal.

DEATON, A., (1991), "Saving and Liquidity Constraints, Econometrica, 59, pp. 1221-1248.

EECKHOUDT, L. and GOLLIER, C., (1995), Risk: Evaluation, Management and Sharing, Harvester Wheatsheaf, Hertfordshire (G.-B.).

EECKHOUDT, L. and GOLLIER, C., (1996), "The Insurance of Low Probability Events", mimeo, University of Toulouse.

GOLLIER, C., (1993), "Economic Theory of Risk Exchanges: A Review, in Contributions to Insurance Economics, G. Dionne Editor, Kluwer Academic Press, pp. 3-23.

GOLLIER, C., (1994), "Insurance and Precautionary Saving in a Continuous-Time Model”, Journal of Risk and Insurance, 61, pp. 78-95.

GOLLIER, C., KOEHL, P.-F. and ROCHET, J.-C., (1997), "Risk-Taking Behaviour with Limited Liability and Risk Aversion", Journal of Risk and Insurance, forthcoming.

GOLLIER, C. and KIMBALL, M. S., (1996), "Toward a systematic approach to the economic effects of uncertainty: Characterizing utility functions", mimeo, University of Michigan.

GILBOA, I. and SCHMEIDLER, (1989), "Maximin expected utility with non-unique prior”, Journal of Mathematical Economics, 18, pp.141-153.

HIRSHLEIFER, J., (1971), "The Private and Social Value of Information and the Reward of Inventive Activity", American Economic Review, 61, pp. 561-574.

HOLMSTROM, B., (1979), "Moral Hazard and Observability", Bell Journal of Economics, 10, pp. 74-91.

KUNREUTHER, H., (1996), "Mitigating Losses and Providing Protection Against Catastrophic Risks: The Role of Insurance and Other Policy Instruments", Geneva Papers on Risk and Insurance Theory, forthcoming.

MOSSIN, J., (1968), “Aspects of Rational Insurance Purchasing”, Journal of Political Economy, 76, pp. 533-568.

RAVIV, A., (1979), "The Design of an Optimal Insurance Policy, American Economic Review, 69, pp. 84-96.

ROCHET, J.-C., (1991), "Incentives, Redistribution, and Social Insurance”, Geneva Papers on Risk and Insurance Theory, 16, pp. 143-165.

SEGAL, U. and SPIVAK, A., (1990), "First Order Versus Second Order Risk Aversion", Journal of Economic Theory, 51, pp. 111-125.

YAARI, M. E., (1976), "A Law of Large Numbers in the Theory of Consumer's Choice under Uncertainty", Journal of Economic Theory, 12, pp. 202-217. 